\title{
Synthesis, Characterization, and Photophysical Properties of Luminescent Gallium and Indium Complexes Constructed using Tridentate 6-Azolyl-2,2'-bipyridine Chelates
}

\author{
Yi-Hwa Song, Yuan-Chieh Chiu, and Yun Chi* \\ Department of Chemistry, National Tsing Hua University, Hsinchu 30013, Taiwan \\ Pi-Tai Chou,* Yi-Ming Cheng, Chun-Wei Lin, and Gene-Hsiang Lee \\ Department of Chemistry and Instrumentation Center, National Taiwan University, Taipei 10617, Taiwan \\ Arthur J. Carty* \\ Steacie Institute for Molecular Sciences, National Research Council, Ontario K1A OR6, Canada
}

Received June 12, 2007

\begin{abstract}
Three systematically functionalized 6-azolyl-2,2'-bipyridine ligands were prepared from reactions initiated by 6 -cyano-2,2'-bipyridine. These ligands readily reacted with the metal alkyl reagents $\mathrm{GaMe}_{3}$ and $\mathrm{InMe}_{3}$ to afford the pentacoordinate complexes [(fpzbpy)MMe $\mathrm{MM}_{2}$ (1), $\left.\mathbf{M}=\mathrm{Ga} ; \mathbf{1 b}, \mathbf{M}=\mathrm{In}\right)$, [(ftzbpy) $\left.\mathrm{MMe}_{2}\right](\mathbf{2 a}, \mathbf{M}=\mathrm{Ga} ; \mathbf{2 b}, \mathbf{M}=\mathrm{In})$, and [(N4bpy)MMe $\left.\mathrm{M}_{2}\right](\mathbf{3 a}, \mathrm{M}=\mathrm{Ga} ; \mathbf{3 b}, \mathbf{M}=\mathrm{In})$, in which (fpzbpy)H, (ftzbpy)H, and (N4bpy)H denote 6-pyrazolyl-, 6-triazolyl-, and 6-tetrazolyl-substituted 2,2'bipyridine, respectively. These complexes exhibited moderate blue-green emission ranging from 412 to $493 \mathrm{~nm}$. On the other hand, treatment of the bidentate 2-pyridyl tetrazole ligand (pyN4)H with $\mathrm{InMe}_{3}$ afforded the bridged dimer $\left[\mathrm{Me}_{2} \operatorname{In}(\mathrm{pyN} 4)\right]_{2}(\mathbf{4})$. Calculation based on time-dependent density function theory (TDDFT) showed that the $\mathrm{S}_{1}$ state of complexes $\mathbf{1 - 3}$ is mainly attributed to an allowed intraligand $\pi \rightarrow \pi^{*}$ electronic transition located at tridentate chelating moieties, together with a small contribution $(<10 \%)$ of gallium (or indium) $\rightarrow \pi^{*}$ (ligand) charge transfer transition. Accordingly, the corresponding emission properties of $\mathbf{1 a}-\mathbf{3 a}$ ( or $\mathbf{1} \mathbf{b}-\mathbf{3 b}$ ) can be rationalized using the correlation between the substituent effect of azolyl groups and the relative HOMO/LUMO energy level.
\end{abstract}

\section{Introduction}

Luminescent main-group-metal compounds have recently received considerable attention, due to their potential use in various applications such as organic light-emitting diodes (OLEDs), ${ }^{1}$ electroluminescence, and fluorescence probes for detection of various anion, cation, or even neutral molecules. ${ }^{2}$ As for the group III metal complexes utilized in the fabrication of OLEDs, the best known family to date should be credited to aluminum-containing molecules such as tris(8-quinolinolate)aluminum(III) $\left(\mathrm{AlQ}_{3}\right){ }^{3}{ }^{3}$ Their functionalized derivatives have shown bright fluorescence ranging from blue to green to red. ${ }^{4} \mathrm{AlQ}_{3}$

* To whom correspondence should be addressed. Fax: +88635720864 (Y.C.); +88622369 5208 (P.-T.C.); +1 6139537592 (A.J.C.). E-mail: ychi@mx.nthu.edu.tw (Y.C.); chop@ntu.edu.tw (P.-T.C.); carty.arthur@ ic.gc.ca (A.J.C.).

(1) (a) Wang, S. Coord. Chem. Rev. 2001, 215, 79. (b) Anderson, S.; Weaver, M. S.; Hudson, A. J. Synth. Met. 2000, 111-112, 459. (c) Li, Y.; Liu, Y.; Bu, W.; Guo, J.; Wang, Y. Chem. Commun. 2000, 1551

(2) (a) Beer, G.; Daub, J.; Rurack, K. Chem. Commun. 2001, 1138. (b) Rurack, K.; Kollmannsberger, M; Resch-Genger, U.; Daub, J. J. Am. Chem. Soc. 2000, 122, 968. (c) Rurack, K.; Kollmannsberger, M.; Daub, J. Angew. Chem., Int. Ed. 2001, 40, 385.

(3) (a) Tang, C. W.; VanSlyke, S. A. Appl. Phys. Lett. 1987, 51, 913. (b) Sapochak, L. S.; Padmaperuma, A.; Washton, N.; Endrino, F.; Schmett, G. T.; Marshall, J.; Fogarty, D.; Burrows, P. E.; Forrest, S. R. J. Am. Chem. Soc. 2001, 123, 6300 .

(4) Montes, V. A.; Pohl, R.; Shinar, J.; Anzenbacher, P. J. Chem. Eur. J. 2006, 12, 4523 . also serves as an electron-transporting and host material currently used in many commercialized light-emitting devices. ${ }^{5}$

In yet another approach, highly luminescent materials were also synthesized for their isoelectronic boron congeners. The synthetic route generally incorporates the treatment of bidentate organic $\pi$-chromophores with boron reagents such as $\mathrm{BPh}_{3}$ and $\mathrm{BF}_{3} \cdot \mathrm{OEt}_{2}$. ${ }^{6}$ During these reactions, the incoming chromophore interacted with the central boron atom and caused the elimination of 1 equiv of benzene or HF, giving air-stable, tetrahedral complexes with one chelating $\pi$-conjugated chromophore. Selected examples of such emissive boron complexes include dipyrromethene dyes (BODIPY) and derivatives, ${ }^{7}$ dibenzometha-

(5) Shinar, J. Organic Light-Emitting Devises-A Survey; Springer: Berlin, 2003

(6) (a) Albrecht, K.; Kaiser, V.; Boese, R.; Adams, J.; Kaufmann, D. E. J. Chem. Soc. Perkin Trans. 2, 2000, 2153. (b) Wu, Q.; Esteghamatian, M.; Hu, N.-X.; Popovic, Z.; Enright, G.; Tao, Y.; D’Iorio, M.; Wang, S. Chem. Mater. 2000, 12, 79. (c) Jia, W.-L.; Song, D.; Wang, S. J. Org. Chem. 2003, 68, 701. (d) Cheng, C.-C.; Yu, W.-S.; Chou, P.-T.; Peng, S.M.; Lee, G.-H.; Wu, P.-C.; Song, Y.-H.; Chi, Y. Chem. Commun. 2003, 2628. (e) Klappa, J. J.; Geers, S. A.; Schmidtke, S. J.; MacManus-Spencer, L. A.; McNeill, K. Dalton Trans. 2004, 883. (f) Chen, H.-Y.; Chi, Y.; Liu, C.-S.; Yu, J.-K.; Cheng, Y.-M.; Chen, K.-S.; Chou, P.-T.; Peng, S.-M.; Lee, G.-H.; Carty, A. J.; Yeh, S.-J.; Chen, C.-T. Adv. Funct. Mater. 2005, $15,567$.

(7) (a) Chen, J.; Burghart, A.; Derecskei-Kovacs, A.; Burgess, K. J. Org. Chem. 2000, 65, 2900. (b) Wan, C.-W.; Burghart, A.; Chen, J.; Bergstroem, F.; Johansson, L. B.-A.; Wolford, M. F.; Kim, T. G.; Topp, M. R.; Hochstrasser, R. M.; Burgess, K. Chem. Eur. J. 2003, 9, 4430. (c) Goze, C.; Ulrich, G.; Mallon, L. J.; Allen, B. D.; Harriman, A.; Ziessel, R J. Am. Chem. Soc. 2006, 128, 10231. 


\section{Chart 1}
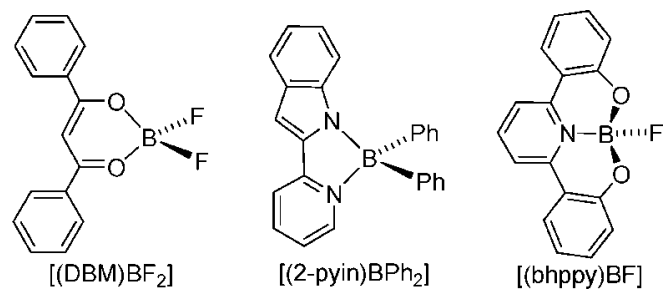

natoboron difluoride $\left((\mathrm{DBM}) \mathrm{BF}_{2}\right),{ }^{8}$ and even $\left[(2-\right.$ pyin $\left.) \mathrm{BPh}_{2}\right](2-$ pyin $=2$-(2-pyridyl)indole) (see Chart 1$),{ }^{9}$ for which the $\mathrm{BPh}_{2}$ or $\mathrm{BF}_{2}$ fragment serves as an anchor to stabilize the planar arrangement of the $\pi$-chromophore and their lowest lying excited states are dominated by the singlet $\pi \pi^{*}$ transition character.

From the viewpoint of molecular design, another class of boron-containing emitter is also obtained by treatment of $\mathrm{BF}_{3}$ with tridentate ligand derived from 1,6-bis(2-hydroxyphenyl)pyridine $\left(\mathrm{H}_{2}\right.$ bhppy). Due to the presence of two acidic phenol functional groups, the reaction proceeded with simultaneous elimination of 2 equiv of $\mathrm{HF}$, giving the tridentate, pseudoplanar complex [(bhppy)BF] as the major product. ${ }^{1 \mathrm{c}}$ The advantages of the aforementioned boron complexes are their good solubility in organic solvents, excellent luminous efficiencies, readily finetuned emission peak wavelength, and facile deposition on substrate surface by means of direct thermal evaporation techniques.

As for their heavy analogues, it has been reported that the gallium metal atom can likewise form the coordinatively saturated complexes tris(8-hydroxyquinaldine)gallium(III $)^{3}$ and bis(8-hydroxyquinaldine)gallium(III) $\left(\mathrm{Q}_{2} \mathrm{GaX}\right.$ with $\mathrm{X}=$ acetate, dimethylpropionate, benzoate, chloro), which have been proved to be useful as the host material, electron-transporting material, and emitter for OLED devices capable of showing good electroluminescent efficiencies at low drive currents. ${ }^{10}$ Nowadays, the emissive gallium complexes have even been extended to other systems; selective examples involve the coordination of $\beta$-ketoiminato chromophores to a single $\mathrm{GaMe}_{2}$ unit $^{11}$ or the formation of the dinuclear gallium complex $\left[\mathrm{Ga}_{2}(\mathrm{saph})_{2} \mathrm{Q}_{2}\right]$ with both chelating salicylidene-o-aminophenolato ligands (saph) and bridging 8-quinolinolato ligands (Q). ${ }^{12}$ Furthermore, the fivecoordinated complexes $\mathrm{Sn}$ (bip) $\mathrm{Ph}_{2}$ and $\mathrm{Pb}$ (bip) $\mathrm{Ph}_{2}\left(\right.$ bipH $_{2}=2,6$ bis(2'-indolyl)pyridine) have been synthesized, showing the versatility of heavy members of the group 14 elements in assembling the potentially useful emitters in OLEDs. ${ }^{13}$

In this article, we wish to report the synthesis, characterization, and theoretical investigation of a new class of gallium and indium complexes bearing substituted 6-azolyl-2,2'-bipyridine ligands. We anticipate that these ligands would serve as excellent tridentate $\pi$-chromophores upon treatment with group III metal

(8) Chow, Y. L.; Liu, Z.-L.; Johansson, C. I.; Ishiyama, J.-I. Chem. Eur. J. 2000, 6, 2942.

(9) Liu, S.-F.; Wu, Q.; Schmider, H. L.; Aziz, H.; Hu, N.-X.; Popovic, Z.; Wang, S. J. Am. Chem. Soc. 2000, 122, 3671.

(10) (a) Hamada, Y.; Kanno, H.; Sano, T.; Fujii, H.; Nishio, Y.; Takahashi, H.; Usuki, T.; Shibata, K. Appl. Phys. Lett. 1998, 72, 1939. (b) Sapochak, L. S.; Burrows, P. E.; Garbuzov, D.; Ho, D. M.; Forrest, S. R.; Thompson, M. E. J. Phys. Chem. 1996, 100, 17766. (c) Crispini, A.; Aiello, I.; La Deda, M.; De Franco, I.; Amati, M.; Lelj, F.; Ghedini, M. Dalton Trans. 2006, 5124.

(11) Shen, Y.; Han, J.; Gu, H.; Zhu, Y.; Pan, Y. J. Organomet. Chem. 2004, 689, 3461.

(12) Qiao, J.; Wang, L. D.; Duan, L.; Li, Y.; Zhang, D. Q.; Qiu, Y. Inorg. Chem. 2004, 43, 5096.

(13) Jia, W.-L.; Liu, Q.-D.; Wang, R.; Wang, S. Organometallics 2003, 22,4070 . alkyl reagents such as $\mathrm{GaMe}_{3}$ and $\mathrm{InMe}_{3}$ under mild conditions, affording a planar, rigid, and highly conjugated $\pi$-system perfectly tailored to enhance their luminescent properties. The tridentate and monoanionic nature of these ligands is expected to facilitate the formation of the pentacoordination mode, which should fit into gallium and indium with a much larger atomic size, as opposed to the smaller boron and aluminum elements, rendering relatively more stable products. In sharp contrast, reaction with a bidentate ligand would afford a dimeric structure, although the same type of pentacoordinate environment can be achieved. ${ }^{14}$ In addition, we anticipate that such a design strategy might conceptually lead to the development of new luminescent molecules with good fluorescence quantum yields ${ }^{3,15}$ and tunable emission hue, potentially suited to the current search for highly luminescent main-group-metal complexes.

\section{Experimental Section}

2.1. General Information and Materials. Mass spectra were obtained on a JEOL SX-102A instrument operating in the electron impact (EI) mode. The ${ }^{1} \mathrm{H}$ NMR spectra were recorded on Varian Mercury-400 or INOVA-500 instruments. Elemental analyses were carried out at the NSC Regional Instrumentation Center at National Chiao Tung University, Hsinchu, Taiwan. The group 13 metal alkyl reagents $\mathrm{GeMe}_{3}$ and $\mathrm{InMe}_{3}$ were provided by Rohm and Haas Co. as free gifts. All reactions were performed under an inert atmosphere using anhydrous solvents or solvents treated with appropriate drying reagents.

2.2. Spectroscopic Measurements. Steady-state absorption and emission spectra were recorded by using a Hitachi (U-3310) spectrophotometer and an Edinburgh (FS920) fluorimeter, respectively. Both the wavelength-dependent excitation and emission responses of the fluorimeter had been calibrated. Lifetime measurements were performed with an Edinburgh FL 900 photocounting system by using a hydrogen-filled or a nitrogen lamp as the excitation source. Data were analyzed by using a nonlinear leastsquares procedure in combination with an iterative convolution method. The emission decays were analyzed by the sum of exponential functions, which allows partial removal of the instrument time broadening and consequently renders a temporal resolution of about $200 \mathrm{ps}$. Quinine sulfate in $1.0 \mathrm{~N}$ sulfuric acid solution was used as a reference, assuming the quantum yield $\Phi_{\mathrm{f}}=0.54,{ }^{16}$ to determine fluorescence quantum yields of the studied compounds in solution. Solution samples were degassed by three freeze-pump-thaw cycles. To acquire the phosphorescence spectrum in the $77 \mathrm{~K} \mathrm{CH}_{3} \mathrm{CN}$ matrix, an Nd:YAG $(355 \mathrm{~nm}, 8 \mathrm{~ns}$, Continuum Surlite II) pumped optical parametric oscillator was tuned between 620 and $800 \mathrm{~nm}$ and was then frequency doubled by BBO crystals to obtain a 310-400 $\mathrm{nm}$ excitation frequency. The resulting luminescence was detected by an intensified charge-coupled detector (ICCD; Princeton Instruments, Model 576G/1) coupled with a polychromator in which the grating is blazed with a maximum at $700 \mathrm{~nm}$. Typically, the gate of the ICCD was opened at a delay time of $100 \mathrm{~ns}$ to avoid scattering light and prompt fluorescence.

2.3. Experimental Procedures. Preparation of (ftzbpy)H. A $25 \mathrm{~mL}$ round-bottom flask was charged with ethyl trifluoroacetate (315 mg, $2.22 \mathrm{mmol})$, hydrazine hydrate (102 $\mu \mathrm{L}, 2.11 \mathrm{mmol})$, and $15 \mathrm{~mL}$ of THF. The mixture was refluxed for $1 \mathrm{~h}$. After the solution was cooled to room temperature, bipyridine carboximidamide hydrochloride (535 mg, $2.28 \mathrm{mmol}$ ) and sodium hydroxide (91 mg,

(14) Examples for the formation of dimeric group III metal complexes showing a pentacoordinated geometry: (a) Park, J. T.; Kim, Y.; Kim, J.; Kim, K.; Kim, Y. Organometallics 1992, 11, 3320. (b) Zhou, Y.; Richeson, D. S. Organometallics 1995, 14, 3558.

(15) Chen, C. H.; Shi, J. Coord. Chem. Rev. 1998, 171, 161.

(16) (a) Melhuish, W. H. J. Phys. Chem. 1961, 65, 229. (b) Demas, J. N.; Crosby, G. A. J. Phys. Chem. 1971, 75, 991. 
$2.28 \mathrm{mmol}$ ) were added into this flask. The reaction mixture was refluxed for another $8 \mathrm{~h}$, the solvent was removed, and the residue was dissolved in ethyl acetate $(40 \mathrm{~mL})$. The organic layer was washed with deionized water $(3 \times 20 \mathrm{~mL})$, dried over anhydrous sodium sulfate, and concentrated to dryness, giving a colorless powdery solid (275 $\mathrm{mg}, 45 \%$ ).

Spectral data of (ftzbpy)H: ${ }^{1} \mathrm{H}$ NMR (400 MHz, $d_{6}$-acetone, 294 $\mathrm{K}): \delta 8.72-8.70(\mathrm{~m}, 2 \mathrm{H}), 8.61(\mathrm{dd}, J=8.0,1.2 \mathrm{~Hz}, 1 \mathrm{H}), 8.23$ $(\mathrm{dd}, J=7.6,1.2 \mathrm{~Hz}, 1 \mathrm{H}), 8.17$ (t, $J=7.6 \mathrm{~Hz}, 1 \mathrm{H}), 7.94(\mathrm{~m}, 1 \mathrm{H})$, 7.46 (ddd, $J=7.4,4.6,1.2 \mathrm{~Hz}, 1 \mathrm{H}$ ).

Preparation of (N4bpy)H. A $25 \mathrm{~mL}$ reaction flask was charged with 6-cyano-2,2'-bipyridine (500 $\mathrm{mg}, 2.76 \mathrm{mmol}$ ), sodium azide (270 mg, $4.14 \mathrm{mmol}$ ), ammonium chloride (220 mg, $4.14 \mathrm{mmol}$ ), and $10 \mathrm{~mL}$ of DMF. The mixture was stirred at $130{ }^{\circ} \mathrm{C}$ for $3 \mathrm{~h}$. After that, the solution was cooled to room temperature and the solvent removed under vacuum. Addition of excess $0.1 \mathrm{~N} \mathrm{HCl}$ solution resulted in formation of a colorless precipitate, which was collected by filtration; yield $460 \mathrm{mg}, 2.04 \mathrm{mmol}, 74 \%$.

Spectral data of (N4bpy)H: ${ }^{1} \mathrm{H}$ NMR (300 MHz, $d_{6}$-acetone, 294 $\mathrm{K}): \delta 8.77-8.71(\mathrm{~m}, 2 \mathrm{H}), 8.67(\mathrm{dd}, J=8.0,1.0 \mathrm{~Hz}, 1 \mathrm{H}), 8.34$ $(\mathrm{dd}, J=7.2,1.0 \mathrm{~Hz}, 1 \mathrm{H}), 8.23(\mathrm{t}, J=8.0 \mathrm{~Hz}, 1 \mathrm{H}), 7.98(\mathrm{td}, J=$ 8.0, 3.6 Hz, 1H), 7.51-7.46 (m, $1 \mathrm{H})$.

Preparation of [(fpzbpy)GaMe $\mathbf{G a}_{2}$ (1a). A $25 \mathrm{~mL}$ reaction flask was charged with (fpzbpy)H (132 mg, $0.46 \mathrm{mmol})$ and $10 \mathrm{~mL}$ of anhydrous diethyl ether. To this solution was added $\mathrm{GaMe}_{3}(50$ $\mu \mathrm{L}, 0.50 \mathrm{mmol}$ ), and the mixture was stirred at room temperature for $1 \mathrm{~h}$. After that, the white precipitate was collected by filtration and washed with diethyl ether. It was then recrystallized using a layered solution of acetone and hexane, giving $130 \mathrm{mg}$ of rhomboidal crystals $(0.33 \mathrm{mmol}, 73 \%)$.

Spectral data of 1a: MS (EI) $m / z$ 373, $(\mathrm{M}-\mathrm{Me})^{+} ;{ }^{1} \mathrm{H}$ NMR $\left(400 \mathrm{MHz}, d_{6}\right.$-acetone, $\left.294 \mathrm{~K}\right) \delta 8.87(\mathrm{dd}, J=5.2,1.6 \mathrm{~Hz}, 1 \mathrm{H}$, $\mathrm{CH}), 8.62(\mathrm{~d}, J=8.0 \mathrm{~Hz}, 1 \mathrm{H}, \mathrm{CH}), 8.51(\mathrm{dd}, J=8.0,0.8 \mathrm{~Hz}, 1 \mathrm{H}$, $\mathrm{CH}), 8.41(\mathrm{t}, J=8.0 \mathrm{~Hz}, 1 \mathrm{H}, \mathrm{CH}), 8.28(\mathrm{td}, J=8.0,1.6 \mathrm{~Hz}, 1 \mathrm{H}$, $\mathrm{CH}), 8.14$ (dd, $J=8.0,0.8 \mathrm{~Hz}, 1 \mathrm{H}, \mathrm{CH}), 7.83(\mathrm{ddd}, J=7.6,5.2$, $1.2 \mathrm{~Hz}, 1 \mathrm{H}, \mathrm{CH}), 7.17$ (s, 1H, CH), -0.26 (s, 6H, Me); ${ }^{13} \mathrm{C}$ NMR $\left(100 \mathrm{MHz}, d_{6}\right.$-acetone, $\left.294 \mathrm{~K}\right) \delta 151.2(\mathrm{~s}, 1 \mathrm{C}, \mathrm{CN}), 149.7(\mathrm{~s}, 1 \mathrm{C}$, $\mathrm{CN}), 148.3(\mathrm{~s}, 1 \mathrm{C}, \mathrm{CN}), 147.8(\mathrm{~s}, 1 \mathrm{C}, \mathrm{CN}), 145.9\left(\mathrm{q}, J_{\mathrm{CF}}=35 \mathrm{~Hz}\right.$, $\left.1 \mathrm{C}, \mathrm{CCF}_{3}\right), 144.3(\mathrm{~s}, 1 \mathrm{C}, \mathrm{CN}), 143.8(\mathrm{~s}, 1 \mathrm{C}, \mathrm{CH}), 140.6(\mathrm{~s}, 1 \mathrm{C}$, $\mathrm{CH}), 127.6(\mathrm{~s}, 1 \mathrm{C}, \mathrm{CH}), 123.9\left(\mathrm{q}, J_{\mathrm{CF}}=267 \mathrm{~Hz}, 1 \mathrm{C}, \mathrm{CF}_{3}\right), 122.6$ (s, 1C, CH), 121.5 (s, 1C, CH), 120.1 (s, 1C, CH), 101.3 (s, 1C, $\mathrm{CH}),-4.5$ (s, 6C, $\left.\mathrm{CH}_{3}\right)$. Anal. Calcd for $\mathrm{C}_{16} \mathrm{H}_{14} \mathrm{~F}_{3} \mathrm{GaN}_{4}$ : N, 14.40; C, 49.40; H, 3.63. Found: N, 14.11; C, 49.32; H, 3.92.

Preparation of [(fpzbpy) $\mathbf{I n M e}_{2}$ ] (1b). A $25 \mathrm{~mL}$ reaction flask was charged with (fpzbpy)H (132 mg, $0.46 \mathrm{mmol})$ and $10 \mathrm{~mL}$ of anhydrous diethyl ether. To this solution was added dropwise $\mathrm{InMe}_{3}$ (80 mg, $0.50 \mathrm{mmol})$ dissolved in diethyl ether $(3 \mathrm{~mL})$, and the mixture was stirred at room temperature for $1 \mathrm{~h}$. After that, the white precipitate was collected by filtration and washed with diethyl ether, giving $125 \mathrm{mg}$ of white product $(0.29 \mathrm{mmol}, 63 \%)$.

Spectral data of 1b: MS (EI) $m / z$ 419, $(\mathrm{M}-\mathrm{Me})^{+} ;{ }^{1} \mathrm{H}$ NMR (400 MHz, $d_{6}$-acetone, $\left.294 \mathrm{~K}\right) \delta 8.86(\mathrm{dd}, J=4.8,2.0 \mathrm{~Hz}, 1 \mathrm{H}$, $\mathrm{CH}), 8.64(\mathrm{~d}, J=8.0 \mathrm{~Hz}, 1 \mathrm{H}, \mathrm{CH}), 8.47$ (dd, $J=8.0,0.8 \mathrm{~Hz}, 1 \mathrm{H}$, $\mathrm{CH}), 8.33(\mathrm{t}, J=8.0 \mathrm{~Hz}, 1 \mathrm{H}, \mathrm{CH}), 8.30(\mathrm{td}, J=8.0,2.0 \mathrm{~Hz}, 1 \mathrm{H}$, $\mathrm{CH}), 8.06(\mathrm{dd}, J=8.0,0.8 \mathrm{~Hz}, 1 \mathrm{H}, \mathrm{CH}), 7.84(\mathrm{ddd}, J=7.2,4.8$, $0.8 \mathrm{~Hz}, 1 \mathrm{H}, \mathrm{CH}), 7.18(\mathrm{~s}, 1 \mathrm{H}, \mathrm{CH}),-0.24(\mathrm{~s}, 6 \mathrm{H}, \mathrm{Me}) ;{ }^{13} \mathrm{C} \mathrm{NMR}$ $\left(100 \mathrm{MHz}, d_{6}\right.$-acetone, $\left.294 \mathrm{~K}\right) \delta 152.0(\mathrm{~s}, 1 \mathrm{C}, \mathrm{CN}), 149.9(\mathrm{~s}, 1 \mathrm{C}$, $\mathrm{CN}), 149.6(\mathrm{~s}, 1 \mathrm{C}, \mathrm{CN}), 148.6(\mathrm{~s}, 1 \mathrm{C}, \mathrm{CN}), 146.2(\mathrm{~s}, 1 \mathrm{C}, \mathrm{CN})$, $145.8\left(\mathrm{q}, J_{\mathrm{CF}}=35 \mathrm{~Hz}, 1 \mathrm{C}, C_{C F}\right), 142.9(\mathrm{~s}, 1 \mathrm{C}, \mathrm{CH}), 141.1(\mathrm{~s}$, $1 \mathrm{C}, \mathrm{CH}), 127.6(\mathrm{~s}, 1 \mathrm{C}, \mathrm{CH}), 124.1$ (q, $\left.J_{\mathrm{CF}}=267 \mathrm{~Hz}, 1 \mathrm{C}, \mathrm{CF}_{3}\right)$, $123.2(\mathrm{~s}, 1 \mathrm{C}, \mathrm{CH}), 122.0(\mathrm{~s}, 1 \mathrm{C}, \mathrm{CH}), 120.4(\mathrm{~s}, 1 \mathrm{C}, \mathrm{CH}), 102.0(\mathrm{~s}$, $1 \mathrm{C}, \mathrm{CH}),-7.3\left(\mathrm{~s}, 6 \mathrm{C}, \mathrm{CH}_{3}\right)$. Anal. Calcd for $\mathrm{C}_{16} \mathrm{H}_{14} \mathrm{~F}_{3} \mathrm{InN}_{4}: \mathrm{N}$, 12.91; C, 44.27; H, 3.25. Found: N, 12.81; C, 44.07; H, 3.62.

Preparation of [(ftzbpy) $\mathrm{GaMe}_{2}$ ] (2a). A $25 \mathrm{~mL}$ reaction flask was charged with (ftzbpy)H $(80 \mathrm{mg}, 0.27 \mathrm{mmol})$ and $10 \mathrm{~mL}$ of anhydrous ether. To this solution was added $\mathrm{GaMe}_{3}(30 \mu \mathrm{L}, 0.30$ $\mathrm{mmol}$ ), and the mixture was stirred at room temperature for $2 \mathrm{~h}$.
After that, the precipitate was filtered and washed with diethyl ether. The sample was recrystallized using a layered solution of acetone and hexane, giving $88 \mathrm{mg}$ of colorless crystal (0.22 mmol, 82\%).

Spectral data of 2a: MS (EI) $\mathrm{m} / \mathrm{z}, 374,(\mathrm{M}-\mathrm{Me})^{+} ;{ }^{1} \mathrm{H}$ NMR (400 MHz, $d_{6}$-acetone, $\left.294 \mathrm{~K}\right) \delta 8.92(\mathrm{dd}, J=5.2,0.8 \mathrm{~Hz}, 1 \mathrm{H}$, $\mathrm{CH}), 8.73-8.70(\mathrm{~m}, 2 \mathrm{H}, \mathrm{CH}), 8.58(\mathrm{t}, J=8.0 \mathrm{~Hz}, 1 \mathrm{H}, \mathrm{CH})$, 8.34-8.32 (m, 2H, CH), 7.90 (dd, $J=7.2,5.2 \mathrm{~Hz}, 1 \mathrm{H}, \mathrm{CH}),-0.21$ (s, 6H, Me). Anal. Calcd for $\mathrm{C}_{15} \mathrm{H}_{13} \mathrm{~F}_{3} \mathrm{GaN}_{5}$ : N, 17.96; C, 46.19; H, 3.36. Found: N, 17.58; C, 46.25; H, 3.70.

Preparation of [(ftzbpy)InMe $\mathbf{I n}_{2}$ (2b). A $25 \mathrm{~mL}$ reaction flask was charged with (ftzbpy)H (100 mg, $0.34 \mathrm{mmol})$ and $10 \mathrm{~mL}$ of anhydrous ether. To this solution was slowly added $\mathrm{InMe}_{3}(60 \mathrm{mg}$, $0.38 \mathrm{mmol})$ dissolved in ether $(3 \mathrm{~mL})$, and the mixture was stirred at room temperature for $1 \mathrm{~h}$. After the reaction was stopped, the solvent was removed and the pale yellow residue was dissolved in acetone. The insoluble precipitate was filtered, and the filtrate was concentrated to dryness, giving a pale yellow powder which was further recrystallized from a layered solution of acetone and hexane; yield $110 \mathrm{mg}, 0.24 \mathrm{mmol}, 72 \%$.

Spectral data of $\mathbf{2 b}$ : MS (EI) $m / z, 420,(\mathrm{M}-\mathrm{Me})^{+} ;{ }^{1} \mathrm{H}$ NMR $\left(400 \mathrm{MHz}, d_{6}\right.$-acetone, $\left.294 \mathrm{~K}\right) \delta 8.91(\mathrm{dd}, J=5.2,0.8 \mathrm{~Hz}, 1 \mathrm{H}$, $\mathrm{CH}), 8.72-8.66(\mathrm{~m}, 2 \mathrm{H}, \mathrm{CH}), 8.48(\mathrm{t}, J=8.0 \mathrm{~Hz}, 1 \mathrm{H}, \mathrm{CH})$, $8.37-8.32$ (m, 2H, CH), 7.88 (dd, $J=7.6,5.2 \mathrm{~Hz}, 1 \mathrm{H}, \mathrm{CH}),-0.18$ (s, 6H, Me). Anal. Calcd for $\mathrm{C}_{15} \mathrm{H}_{13} \mathrm{~F}_{3} \mathrm{InN}_{5}: \mathrm{N}, 16.10 ; \mathrm{C}, 41.41 ; \mathrm{H}$, 3.01. Found: N, 15.61; C, 41.36; H, 3.30.

Preparation of [(N4bpy)GaMe $\mathbf{G a}_{2}$ (3a). Following the previously mentioned procedure, 3a was prepared by combining (N4bpy)H (140 mg, $0.62 \mathrm{mmol})$ and $\mathrm{GaMe}_{3}(69 \mu \mathrm{L}, 0.69 \mathrm{mmol})$ in $10 \mathrm{~mL}$ of diethyl ether, and the mixture was stirred at room temperature for $2 \mathrm{~h}$. After removal of the solvent, the product was recrystallized using a layered solution of acetone and hexane, giving $140 \mathrm{mg}$ of colorless crystals $(0.43 \mathrm{mmol}, 69 \%)$.

Spectral data of 3a: MS (EI) $m / z$ 307, $(\mathrm{M}-\mathrm{Me})^{+} ;{ }^{1} \mathrm{H}$ NMR $\left(400 \mathrm{MHz}, d_{6}\right.$-acetone, $\left.294 \mathrm{~K}\right) \delta 8.94(\mathrm{dd}, J=4.8,0.8 \mathrm{~Hz}, 1 \mathrm{H}$, $\mathrm{CH}), 8.77-8.73(\mathrm{~m}, 2 \mathrm{H}, \mathrm{CH}), 8.62(\mathrm{t}, J=8.0 \mathrm{~Hz}, 1 \mathrm{H}, \mathrm{CH}), 8.46$ $(\mathrm{d}, J=8.4 \mathrm{~Hz}, 1 \mathrm{H}, \mathrm{CH}), 8.37(\mathrm{td}, J=8.0,1.6 \mathrm{~Hz}, 1 \mathrm{H}, \mathrm{CH}), 7.92$ (dd, $J=7.6,4.8 \mathrm{~Hz}, 1 \mathrm{H}, \mathrm{CH}),-0.18(\mathrm{~s}, 6 \mathrm{H}, \mathrm{Me})$. Anal. Calcd for $\mathrm{C}_{13} \mathrm{H}_{13} \mathrm{GaN}_{6}$ : N, 26.02; C, 48.34; H, 4.06. Found: N, 26.12; C, 48.39; H, 4.59.

Preparation of [(N4bpy)InMe $\mathbf{I}_{2}$ (3b). Following the previously mentioned procedure, $\mathbf{3 b}$ was prepared by combining (N4bpy)H (102 mg, $0.46 \mathrm{mmol})$ and $\mathrm{InMe}_{3}(80 \mathrm{mg}, 0.50 \mathrm{mmol})$ in $10 \mathrm{~mL}$ of diethyl ether, and the mixture was stirred at room temperature for $2 \mathrm{~h}$. After removal of the solvent, purification was conducted by recrystallization using a layered solution of acetone and hexane, giving $115 \mathrm{mg}$ of colorless crystals $(0.32 \mathrm{mmol}, 69 \%)$.

Spectral data of 3b: MS (EI) $m / z, 353,(\mathrm{M}-\mathrm{Me})^{+}$.; ${ }^{1} \mathrm{H}$ NMR (400 MHz, $d_{6}$-acetone, $\left.294 \mathrm{~K}\right) \delta 8.95(\mathrm{dd}, J=4.8,1.6 \mathrm{~Hz}, 1 \mathrm{H}$, $\mathrm{CH}), 8.73(\mathrm{~d}, J=8.0 \mathrm{~Hz}, 1 \mathrm{H}, \mathrm{CH}), 8.71(\mathrm{dd}, J=8.0,1.2 \mathrm{~Hz}, 1 \mathrm{H}$, $\mathrm{CH}), 8.53$ (t, $J=8.0 \mathrm{~Hz}, 1 \mathrm{H}, \mathrm{CH}), 8.47$ (dd, $J=8.0,1.2 \mathrm{~Hz}, 1 \mathrm{H}$, $\mathrm{CH}), 8.36(\mathrm{td}, J=8.0,1.6 \mathrm{~Hz}, 1 \mathrm{H}, \mathrm{CH}), 7.90(\mathrm{ddd}, J=8.0,4.8$, $0.8 \mathrm{~Hz}, 1 \mathrm{H}, \mathrm{CH}),-0.16(\mathrm{~s}, 6 \mathrm{H}, \mathrm{Me})$. Anal. Calcd for $\mathrm{C}_{13} \mathrm{H}_{13} \mathrm{InN}_{6}$ : N, 22.83; C, 42.42; H, 3.56. Found: N, 22.66; C, 42.25; H, 3.97.

Preparation of $\left[\mathrm{Me}_{2} I n(p y N 4)\right]_{2}$ (4). Following the previously mentioned procedure, 4 was prepared by combining (N4py)H (147 $\mathrm{mg}, 1.0 \mathrm{mmol})$ and $\mathrm{InMe}_{3}(176 \mathrm{mg}, 1.1 \mathrm{mmol})$ in $15 \mathrm{~mL}$ of diethyl ether, and the mixture was stirred at room temperature for $1 \mathrm{~h}$. After removal of the solvent, the sample was recrystallized from acetone at room temperature, giving $123 \mathrm{mg}$ of colorless crystals (0.43 mmol, 85\%).

Spectral data of 4: MS (EI) $\mathrm{m} / z$ 567, $(\mathrm{M}-\mathrm{Me})^{+} ;{ }^{1} \mathrm{H}$ NMR $\left(400 \mathrm{MHz}, d_{6}\right.$-acetone, $\left.294 \mathrm{~K}\right) \delta 8.90(\mathrm{~d}, J=4.4 \mathrm{~Hz}, 1 \mathrm{H}, \mathrm{CH})$, $8.41(\mathrm{~d}, J=8.0 \mathrm{~Hz}, 1 \mathrm{H}, \mathrm{CH}), 8.29(\mathrm{td}, J=8.0,1.6 \mathrm{~Hz}, 1 \mathrm{H}, \mathrm{CH})$, 7.78 (ddd, $J=8.0,4.4,1.2 \mathrm{~Hz}, 1 \mathrm{H}, \mathrm{CH}),-0.05(\mathrm{~s}, 6 \mathrm{H}, \mathrm{Me}) ;{ }^{13} \mathrm{C}$ NMR (100 MHz, $d_{4}$-methanol, $\left.294 \mathrm{~K}\right) \delta 161.1$ (s, 2C, CN), 149.3 (s, 2C, CN), 146.7 (s, 2C, CN), 141.4 (s, 2C, CH), 127.0 (s, 2C, $\mathrm{CH}), 122.9(\mathrm{~s}, 2 \mathrm{C}, \mathrm{CH}),-6.2\left(\mathrm{~s}, 12 \mathrm{C}, \mathrm{CH}_{3}\right)$. Anal. Calcd for 
$\mathrm{C}_{16} \mathrm{H}_{20} \mathrm{In}_{2} \mathrm{~N}_{10}: \mathrm{N}, 24.07 ; \mathrm{C}, 33.02 ; \mathrm{H}, 3.46$. Found: N, 23.60; C, $33.21 ; \mathrm{H}, 3.70$.

2.4. Structural Determination. Single-crystal $X$-ray diffraction data were measured on a Bruker SMART CCD diffractometer $\left(2 \theta_{\max } \leq 55.0^{\circ}, \omega\right.$ scan mode $)$ equipped with a graphite monochromator. The data collection was executed using the SMART program. Cell refinement and data reduction were accomplished using the SAINT program. The structures were solved using the SHELXTL/PC package and refined using full-matrix least squares. An empirical absorption correction was applied with the SADABS routine (part of the SHELXTL program). The structure was solved by direct methods using the SHELXTL suite of programs. All nonhydrogen atoms were refined anisotropically by full-matrix least squares on $F^{2}$. Hydrogen atoms were placed in calculated positions and allowed to ride on the parent atoms.

Selected crystal data of 1a: $\mathrm{C}_{16} \mathrm{H}_{14} \mathrm{~F}_{3} \mathrm{GaN}_{4}, M_{\mathrm{r}}=389.03$, monoclinic, space group $P 2_{1} / c, a=8.9197(5), b=14.9354(8), c$ $=12.4181(7) \AA, \beta=100.740(1)^{\circ}, V=1625.35(16) \AA^{3}, Z=4$, $\rho_{\text {calcd }}=1.590 \mathrm{~g} \mathrm{~cm}^{-3}, F(000)=784$, crystal size $0.45 \times 0.30 \times$ $0.25 \mathrm{~mm}, \lambda($ Mo K $\alpha)=0.71073 \AA, T=150(2) \mathrm{K}, \mu=1.729$ $\mathrm{mm}^{-1}$, index ranges $-11 \leq h \leq 11,-19 \leq k \leq 19,-16 \leq l \leq$ 16,14245 reflections collected, 3745 with $R$ (int) $=0.0319$, final $\mathrm{wR} 2($ all data $)=0.0744, \mathrm{R} 1(I>2 \sigma(I))=0.0309$.

Selected crystal data of $4: \mathrm{C}_{16} \mathrm{H}_{20} \mathrm{In}_{2} \mathrm{~N}_{10}, M_{\mathrm{r}}=582.06$, triclinic, space group $P \overline{1}, a=6.8471(6) \AA, b=8.6997(7) \AA, c=9.0856(7)$ $\AA, \alpha=88.128(2)^{\circ}, \beta=82.900(2)^{\circ}, \gamma=70.894(2)^{\circ}, V=507.46(7)$ $\AA^{3}, Z=1, \rho_{\text {calcd }}=1.905 \mathrm{gcm}^{-1}, \mu=2.296 \mathrm{~mm}^{-1}, F(000)=284$,

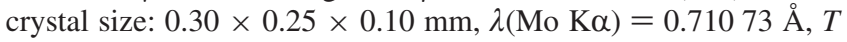
$=150(2) \mathrm{K}$, index ranges $-8 \leq h \leq 8,-11 \leq k \leq 11,-11 \leq l$ $\leq 11,6633$ reflections collected, 2322 with $R$ (int) $=0.0212$, final $\mathrm{wR} 2($ all data $)=0.0435 . \mathrm{R} 1(I>2 \sigma(I))=0.0171$.

2.5. Theoretical Approach. Calculations on the electronic ground state of complexes $\mathbf{1 a}-\mathbf{3 a}$ and $\mathbf{1 b}-\mathbf{3 b}$ were carried out by using B3LYP density functional theory. ${ }^{17} \mathrm{~A}$ "double- $\zeta$ ” quality basis set consisting of the Hay and Wadt effective core potentials $\left(\right.$ LANL2DZ) ${ }^{18}$ was employed for the In and Ga atoms and 6-31G* basis for $\mathrm{H}, \mathrm{C}, \mathrm{N}$, and $\mathrm{F}$ atoms. ${ }^{19}$ Time-dependent DFT (TDDFT) calculations using the B3LYP functional were then performed on the basis of the structural optimized geometries in combination with an integral equation formalism-polarizable continuum model (in acetonitrile), IEF-PCM, implemented in Gaussian $03 .{ }^{20}$ Oscillator strengths $(f)$ were deduced from the dipole transition matrix elements (for singlet states only). The ground-state B3LYP and excited-state TDDFT calculations were carried out by using Gaussian $03 .{ }^{21}$ In the frontier region, neighboring orbitals are often closely spaced. In such cases, consideration of only the HOMO and LUMO may not yield a realistic description. For this reason, partial density of states (PDOS) diagrams, which incorporate a degree of overlap between the curves convoluted from neighboring energy levels, can give a more representative picture. The contribution of a group to a molecular orbital was calculated within the framework of Mulliken population analysis. The PDOS spectra were created by convoluting the molecular orbital information with Gaussian curves of unit height and fwhm of $0.5 \mathrm{eV}$. The PDOS diagrams for $\mathbf{1 a}$ and $\mathbf{1 b}$, shown in this work, are generated using the AOMix program. ${ }^{22}$

(17) (a) Becke, A. D. Phys. Rev. A 1988, 38, 3098. (b) Lee, C.; Yang, W.; Parr, R. G. Phys. Rev. B 1988, 37, 785. (c) Miehlich, B.; Savin, A.; Stoll, H.; Preuss, H. Chem. Phys. Lett. 1989, 157, 200.

(18) (a) Hay, P. J.; Wadt, W. R. J. Chem. Phys. 1985, 82, 270. (b) Wadt, W. R.; Hay, P. J. J. Chem. Phys. 1985, 82, 284. (c) Hay, P. J.; Wadt, W. R. J. Chem. Phys. 1985, 82, 299.

(19) Hariharan, P. C.; Pople, J. A. Mol. Phys. 1974, 27, 209.

(20) Cances, E.; Mennucci, B.; Tomasi, J. J. Chem. Phys. 1997, 107, 3032.

(21) Gaussian 03, revision C.02; Gaussian, Inc.: Wallingford, CT, 2004.

(22) (a) Gorelsky, S. I. AOMix, revision 6.33; http://www.sg-chem.net/. (b) Gorelsky, S. I.; Lever, A. B. P. J. Organomet. Chem. 2001, 635, 187.

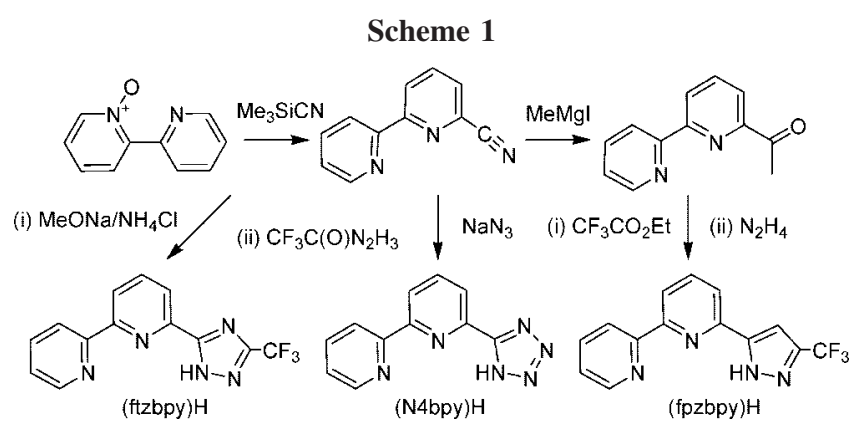

Chart 2

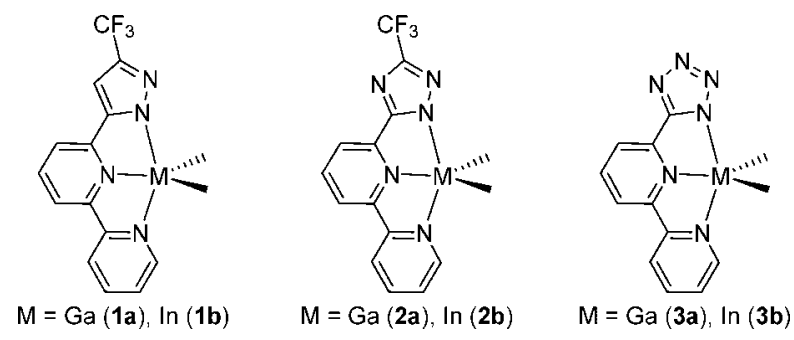

\section{Results and Discussion}

3.1. Ligand Syntheses. As depicted in Scheme 1, synthesis of all the tridentate ligands (fpzbpy) $\mathrm{H},(\mathrm{ftzbpy}) \mathrm{H}$, and $(\mathrm{N} 4 b p y) \mathrm{H}$ required the key starting material 6-cyano-2,2'-bipyridine, which was best prepared by partial oxidation of commercially available 2,2'-bipyridine with $m$-chloroperbenzoic acid to afford 2,2'bipyridine $N$-oxide, followed by treatment with trimethylsilyl cyanide. $^{23}$ The pyrazolyl ligand (fpzbpy)H was best obtained by sequential reactions involving the treatment of methylmagnesium iodide with 6-cyano-2,2'-bipyridine to afford 6-acetyl$2,2^{\prime}$-bipyridine, followed by condensation of 6-acetyl-2,2'bipyridine with ethyl trifluoroacetate, and finally with an excess of hydrazine hydrate in refluxing ethanol solution. ${ }^{24,25}$ The preparation of the triazolyl ligand (ftzbpy)H was conducted by the condensation of trifluoroacetic acid hydrazide with bipyridine carboximidamide hydrochloride; the latter was synthesized by mixing 6-cyano-2,2'-bipyridine with sodium methoxide, followed by reacting with ammonium chloride in refluxing ethanol solution. ${ }^{26}$ The tetrazolyl ligand (N4bpy)H was prepared readily by combining 6-cyano-2,2'-bipyridine with sodium azide and ammonium chloride in DMF solution. ${ }^{27}$

3.2. Preparation and Characterization. Treatment of these 6-azolyl-2,2'-bipyridine ligands with the gallium reagent $\mathrm{GaMe}_{3}$ in anhydrous diethyl ether at room temperature afforded the target $\mathrm{GaMe}_{2}$ complexes $\mathbf{1 a}-\mathbf{3 a}$ in yields of $\geq 70 \%$, while the indium analogues $\mathbf{1 b} \mathbf{- 3} \mathbf{b}$ were synthesized using the indium alkyl reagent $\mathrm{InMe}_{3}$ under similar conditions (Chart 2). All six metal complexes were found to be soluble in common organic solvents such as THF, acetonitrile, and acetone. Moreover, they turned much less stable upon dissolving in chlorinated solvents

(23) Norrby, T.; Borje, A.; Zhang, L.; Akermark, B. Acta Chem. Scand. 1998, 52,77 .

(24) Constable, E. C.; Heirtzler, F.; Neuburger, M.; Zehnder, M. J. Am. Chem. Soc. 1997, 119, 5606.

(25) (a) Chen, K.; Cheng, Y.-M.; Chi, Y.; Ho, M.-L.; Lai, C.-H.; Chou, P.-T.; Peng, S.-M.; Lee, G.-H. Chem. Asian J. 2007, 2, 155. (b) Chen, K.-S.; Liu, W.-H.; Wang, Y.-H.; Lai, C.-H.; Chou, P.-T.; Lee, G.-H.; Chen, K. ; Chen, H.-Y.; Chi, Y.; Du, C.-C. Adv. Funct. Mater. 2007, in press.

(26) Funabiki, K.; Noma, N.; Kuzuya, G.; Matsui, M.; Shibata, K. J. Chem. Res. (Miniprint) 1999, 1301.

(27) Facchetti, A.; Abbotto, A.; Beverina, L.; Bradanante, S.; Mariani, P.; Stern, C. L.; Marks, T. J.; Vacca, A.; Pagani, G. A. Chem. Commun. 2004, 15, 1770 . 


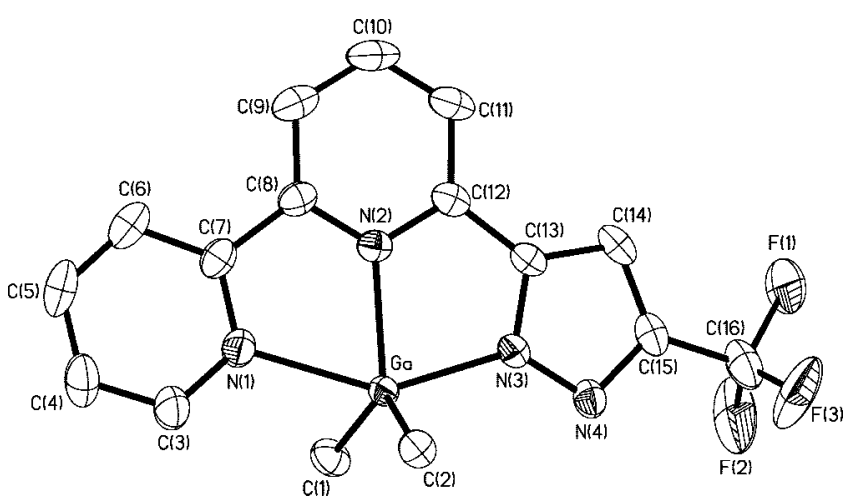

Figure 1. ORTEP diagram of 1a, with thermal ellipsoids shown at the $50 \%$ probability level. Selected bond distances $(\AA)$ and angles (deg): $\mathrm{Ga}-\mathrm{C}(1)=1.967(2), \mathrm{Ga}-\mathrm{C}(2)=1.954(2), \mathrm{Ga}-\mathrm{N}(1)=$ $2.287(2), \mathrm{Ga}-\mathrm{N}(2)=2.100(2), \mathrm{Ga}-\mathrm{N}(3)=2.086(2) ; \mathrm{N}(1)-\mathrm{Ga}-\mathrm{N}(3)$ $=148.14(7), \mathrm{C}(1)-\mathrm{Ga}-\mathrm{C}(2)=124.49(9)$.

such as $\mathrm{CH}_{2} \mathrm{Cl}_{2}$ and $\mathrm{CHCl}_{3}$, as demonstrated by the gradual formation of an insoluble white precipitate over a period of $\sim 2$ $\mathrm{h}$. While the fundamental approach of this class of compounds can be fully accessed with good accuracy, their poor stability may limit their practical applications.

All of these metal complexes were characterized using routine spectroscopic methods as well as elemental analyses. Their spectroscopic data, particularly the high-field ${ }^{1} \mathrm{H}$ NMR signals observed in the region $\delta-0.16$ to -0.26 , are in good agreement with the chemical shifts shown for the group $13 \mathrm{MMe}_{2}$ fragment. $^{28}$ This structural feature was also confirmed by a single-crystal X-ray diffraction study on 1a. As shown in Figure 1, the central gallium atom exhibits a distorted trigonalbipyramidal geometry, with two equatorial methyl substituents $(\mathrm{Ga}-\mathrm{C}(1)=1.967(2) \AA$ and $\mathrm{Ga}-\mathrm{C}(2)=1.954(2) \AA)$ and two distinctive $\mathrm{Ga}-\mathrm{N}$ separations $(\mathrm{Ga}-\mathrm{N}(1)=2.287(2) \AA$ and $\mathrm{Ga}-\mathrm{N}(3)=2.086(2) \AA)$ at the axial sites. The bond angle between these axial coordination atoms showed significant deviation from linearity $\left(\angle \mathrm{N}(1)-\mathrm{Ga}-\mathrm{N}(3)=148.14(7)^{\circ}\right)$, which is due to the formation of two highly constrained chelate rings. Interestingly, the gross structure of 1a is akin to that of the indium complex $\left[(\mathrm{keim}) \mathrm{InMe}_{2}\right],{ }^{29}$ where $(\mathrm{keim}) \mathrm{H}$ is a tridentate ketoimine ligand with the empirical formula $\mathrm{O}=\mathrm{C}\left(\mathrm{CF}_{3}\right) \mathrm{CH}_{2} \mathrm{C}\left(\mathrm{CF}_{3}\right)=\mathrm{NCH}_{2} \mathrm{CH}_{2} \mathrm{NMe}_{2}$, as well as the $\beta$-diketonate gallium complex $\left[(\mathrm{hfac}) \mathrm{GaMe}_{2}(\mathrm{py})\right],{ }^{30}$ for which the combined bonding pattern of ligated pyridine (py) and hexafluoroacetylacetonate (hfac) resembles that of the tridentate fpzbpy chelate observed in $\mathbf{1 a}$.

With a goal of extending the reaction scope, as depicted in Chart 3, we have also examined the condensation of $\mathrm{GaMe}_{3}$ and $\mathrm{InMe}_{3}$ with the corresponding bidentate 2-pyridyl azole ligands such as (pyfpz)H, (pyftz)H,and (pyN4)H. Interesting, only the reaction of (pyN4) $\mathrm{H}^{27}$ and $\mathrm{InMe}_{3}$ produced the anticipated, air-stable complex $\left[\mathrm{Me}_{2} \operatorname{In}(\mathrm{pyN} 4)\right]_{2}$ (4). Other synthetic attempts employing both (pyfpz)H and (pyftz)H ligands have afforded products that decomposed upon removing the $\mathrm{N}_{2}$ atmosphere during workup. A single-crystal X-ray diffraction study on $\mathbf{4}$ was performed in order to establish its molecular structure.

(28) Chi, Y.; Chou, T.-Y.; Wang, Y.-J.; Huang, S.-F.; Carty, A. J.; Scoles, L.; Udachin, K. A.; Peng, S.-M.; Lee, G.-H. Organometallics 2004, 23,95 .

(29) Chou, T.-Y.; Huang, S.-F.; Chi, Y.; Liu, C.-S.; Carty, A. J.; Scoles, L.; Udachin, K. A. Inorg. Chem. 2003, 42, 6041.

(30) Beachley, O. T. J.; Gardinier, J. R.; Churchill, M. R.; Toomey, L. M. Organometallics 1998, 17, 1101.
Chart 3
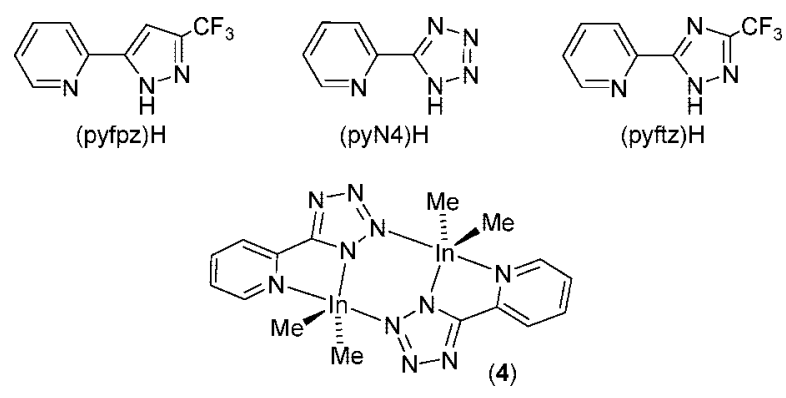

As shown in Figure 2, complex 4 consists of a dimeric arrangement, in which the framework is linked by a pair of bridging tetrazolate ligands. The overall molecular geometry and its symmetric $\operatorname{In}_{2} \mathrm{~N}_{4}$ core arrangement resembles that of the dinuclear indium(III) complex with two bridging 3-(2-pyridyl)pyrazolate ligands, ${ }^{31}$ while each indium metal atom adopts a distorted-trigonal-bipyramidal geometry with the equatorial methyl groups residing above and below with respect to the central $\mathrm{In}_{2} \mathrm{~N}_{4}$ pseudohexagon. It is notable that the $\mathrm{Me}-\mathrm{In}-\mathrm{Me}$ angles of $\sim 143^{\circ}$ in 4 are significantly larger than the Me-In-Me angle observed in $\mathbf{1 b}\left(\sim 130^{\circ}\right)$. The bridging tetrazolate groups span both axial and equatorial positions of In atoms, with the In $-\mathrm{N}_{\mathrm{eq}}$ distances $(\mathrm{In}-\mathrm{N}(5)=2.273(2) \AA)$ being shorter compared with the $\mathrm{In}-\mathrm{N}_{\mathrm{ax}}$ distances $(\mathrm{In}-\mathrm{N}(4 \mathrm{~A})=2.427(3) \AA)$. The $\mathrm{In}-\mathrm{N}_{\mathrm{py}}$ bond occupies the nonbridged axial positions with $\mathrm{In}-\mathrm{N}(1)=2.474(3) \AA$.

On the basis of the crystal structure of $\mathbf{4}$, it becomes obvious that the $3-\mathrm{CF}_{3}$ substituent on the pyfpz and pyftz ligands should introduce significant steric interference with the methyl groups of adjacent $\mathrm{GaMe}_{2}$ or InMe $\mathrm{H}_{2}$ units, if the anticipated pyrazolate and triazolate analogues $\left[\mathrm{Me}_{2} \mathrm{M}(\mathrm{pyfpz})\right]_{2}$ and $\left[\mathrm{Me}_{2} \mathrm{M}(\mathrm{pyftz})\right]_{2}$ $(\mathrm{M}=\mathrm{Ga}$, In) can be generated from the treatment of the corresponding 2-pyridyl azole ligands with the alkyl reagents $\mathrm{GaMe}_{3}$ and $\mathrm{InMe}_{3}$. This hypothesis could perhaps explain the high reactivity of these complexes. However, the poor chemical stability of the $\mathrm{Ga}$ analogue of 4 , i.e. $\left[\left(\mathrm{pyN}_{4}\right) \mathrm{GaMe}_{2}\right]_{2}$, cannot be attributed to this aforementioned steric interaction but is rather due to the greater bond strain imposed by the relatively smaller Ga metal atom.

3.3. Photophysical Properties. The absorption spectra of complexes $\mathbf{1 a}-\mathbf{3 b}$ in $\mathrm{CH}_{3} \mathrm{CN}$ are shown in Figure 3. The strong absorption bands $\left(\epsilon>10^{4} \mathrm{M}^{-1} \mathrm{~cm}^{-1}\right)$ in the UV region are assigned to the spin-allowed ${ }^{1} \pi \pi^{*}$ transitions of the bipyridyl azolate ligands. It is notable that all complexes with the same core atom have very similar absorption spectral features, except that the absorption peak wavelengths are blue-shifted with respect to the tridentate ligand in the order fpzbpy $<$ ftzbpy $<$ N4bpy. For example, the peak wavelength tends to decrease from 1a $(\sim 344 \mathrm{~nm})$ to 3a $(324 \mathrm{~nm})$ as well as from 1b $(340$ $\mathrm{nm})$ to $\mathbf{3 b}(321 \mathrm{~nm})$. Such a spectral difference for both the a and $\mathbf{b}$ series manifests the intrinsic properties of the azolate moiety (i.e., pyrazolate, triazolate, or tetrazolate), which imposes a major influence on the photophysical properties of the associated complexes (vide infra). Moreover, for Ga and In complexes possessing the same ligands, a gradual blue shift of a few hundreds of $\mathrm{cm}^{-1}$ for the In complexes was generally observed (see Table 1). Similar to those of the absorption spectra, the emission peaks (in term of wavelength) of $\mathbf{1 a}-\mathbf{3 a}$

(31) Ward, M. D.; Mann, K. L. V.; Jeffery, J. C.; McCleverty, J. A. Acta Crystallogr., Sect. C 1998, C54, 601. 


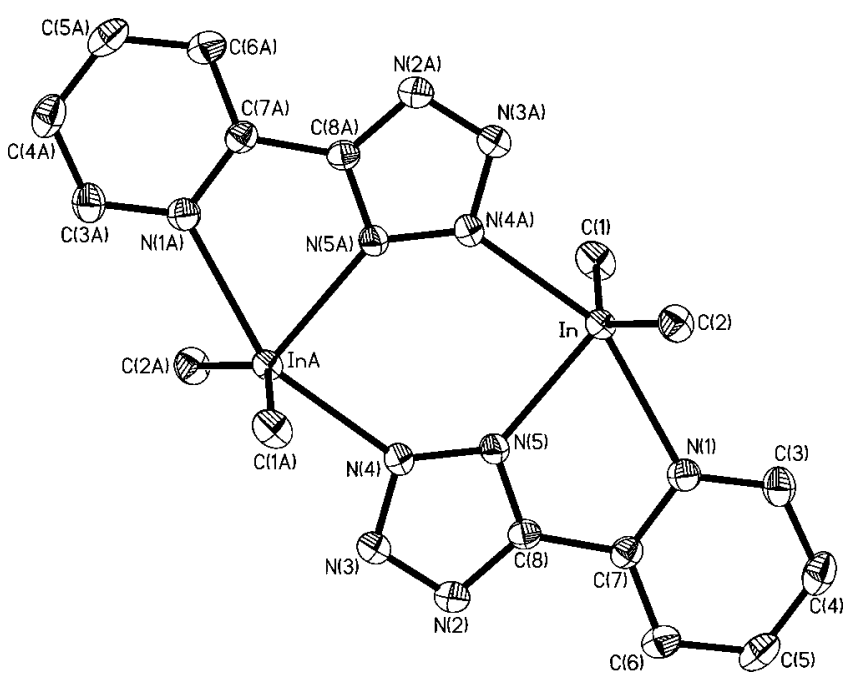

Figure 2. ORTEP diagram of $\mathbf{4}$, with thermal ellipsoids shown at the $50 \%$ probability level. Selected bond distances $(\AA)$ and angles (deg): $\mathrm{In}-\mathrm{C}(1)=2.138(3), \mathrm{In}-\mathrm{C}(2)=2.127(3), \mathrm{In}-\mathrm{N}(5)=$ $2.273(2), \mathrm{In}-\mathrm{N}(4 \mathrm{~A})=2.427(3), \mathrm{In}-\mathrm{N}(1)=2.474(3) ; \mathrm{N}(4 \mathrm{~A})-\mathrm{In}-\mathrm{N}(1)$ $=154.69(5), \mathrm{C}(1)-\mathrm{In}-\mathrm{C}(2)=143.78(8)$.

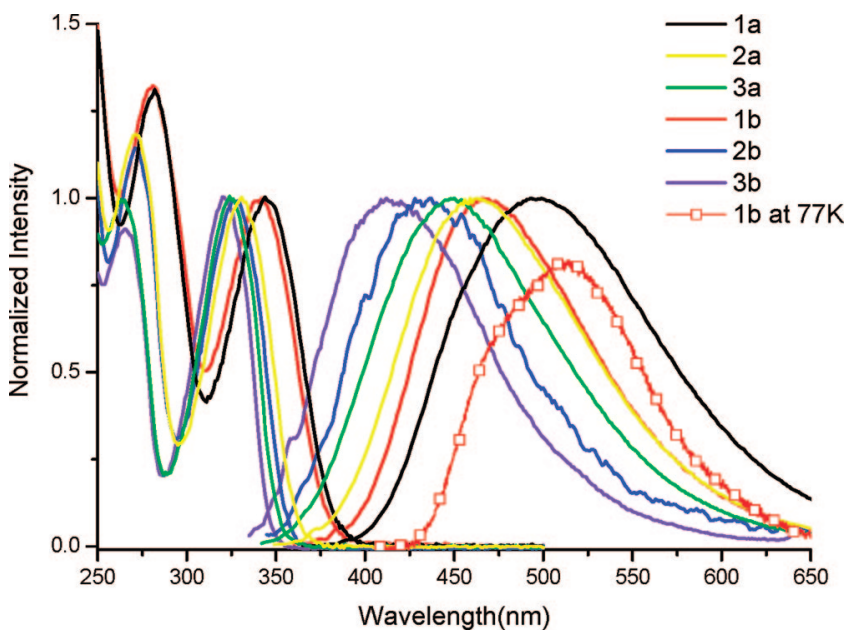

Figure 3. Normalized absorption and luminescence spectra of $\mathbf{1 a}-\mathbf{3 b}$ in $\mathrm{CH}_{3} \mathrm{CN}$ recorded at room temperature (solid lines) and the phosphorescence spectrum of $\mathbf{1 b}$ in a $77 \mathrm{~K} \mathrm{CH}_{3} \mathrm{CN}$ matrix $(-\square-)$, for which the data was acquired at a delay time of $100 \mathrm{~ns}$ (see the Experimental Section). Note that the phosphorescence of 1b is not normalized, to emphasize its transition in different multiplicities.

Table 1. Photophysical Data of Complexes $1 a-3 b$, Measured in Degassed $\mathrm{CH}_{3} \mathrm{CN}$ solution at Room Temperature

\begin{tabular}{lcclcc}
\hline & $\begin{array}{c}\text { abs } \lambda_{\max }(\mathrm{nm}) \\
\left(\epsilon \times 10^{-3}\right)\end{array}$ & em $\lambda_{\max }(\mathrm{nm})$ & $\mathrm{QY}$ & $\tau_{\mathrm{obs}}(\mathrm{ns})$ & \multicolumn{1}{c}{$k_{\mathrm{r}}$} \\
\hline 1a & $282(14.8), 344(11.2)$ & 493 & 0.11 & 2.01 & $5.5 \times 10^{7}$ \\
2a & $271(14.8), 330(12.1)$ & 459 & 0.077 & 0.32 & $2.4 \times 10^{8}$ \\
3a & $263(13.1), 324(13.1)$ & 450 & 0.073 & 0.86 & $8.5 \times 10^{7}$ \\
1b & $281(13.4), 340(10.4)$ & 466 & 0.03 & 1.26 & $2.4 \times 10^{7}$ \\
2b & $271(15.0), 327(13.0)$ & 432 & 0.008 & 0.76 & $1.5 \times 10^{7}$ \\
3b & $265(12.3), 321(13.4)$ & 412 & 0.01 & $<0.3$ & $4.2 \times 10^{7}$ \\
4 & $241(18.6), 283(15.4)$ & 347 & 0.046 & 1.8 & $2.6 \times 10^{7}$
\end{tabular}

follows a trend of $\mathbf{1 a}(493 \mathrm{~nm})>\mathbf{2 a}(459 \mathrm{~nm})>\mathbf{3 a}(450 \mathrm{~nm})$ as well as $\mathbf{1 b}(466 \mathrm{~nm})>\mathbf{2 b}(432 \mathrm{~nm})>\mathbf{3 b}(412 \mathrm{~nm})$ (see Table 1).

In view of the luminescent intensity, all Ga complexes (1a-3a) exhibit moderate $(\sim 0.08-0.11)$ emission quantum yield in $\mathrm{CH}_{3} \mathrm{CN}$, while it is relatively weaker $(\sim 0.01-0.03)$ in the In complexes $(\mathbf{1} \mathbf{b}-\mathbf{3 b})$ under identical condition. The emission intensity is independent of aerated or degassed solution, and the observed lifetimes, $\tau_{\text {obs }}$, were measured to be $<3$ ns (see Table 1). The radiative lifetime calculated by $\tau_{\mathrm{f}}=\tau_{\mathrm{obs}} / \Phi$, where $\Phi$ denotes the emission yield, is deduced to be s few tenths of nanosecondd for $\mathbf{1} \mathbf{a}-\mathbf{3 b}$. Accordingly, for all complexes, the assignment of the emission to a spin-allowed transition, i.e. fluorescence, is unambiguous.

For the dimeric tetrazolate complex $\mathbf{4}$, the lowest lying singlet absorption and emission peak wavelengths were found to be located at 283 and $347 \mathrm{~nm}$, respectively (see Table 1). In comparison with the case for the tridentate analogue $\mathbf{3 b}$, such a large energy gap for absorption (emission) can be tentatively rationalized by the lack of a third pyridyl group to further reduce the LUMO energy level in complex 4. Obviously, complex 4 belongs to an unusual class of UV-emitting materials. ${ }^{32}$ Since our main focus in this study is on the visible emission, a detailed correlation between structure and photophysical properties for 4 was not further pursued.

As concluded for numerous pyridyl-azolate/late-transitionmetal complexes, ${ }^{33}$ if one assumes that the lowest lying singlet excited state is mainly associated with a charge-transfer character from azolate (HOMO) to the pyridyl (LUMO) moiety, the resulting absorption and emission spectra for both $\mathrm{Ga}$ and In complexes may be qualitatively rationalized by a gradual increase of the number of electron-withdrawing nitrogen atoms inside the azolate ring, namely from fpzbpy (two nitrogens), ftzbpy (three nitrogens) to N4bpy (four nitrogens), resulting in the lowering of HOMO energy and hence an increase in the HOMO-LUMO energy gap. In addition, comparison of different metal elements possessing the same ligand environment, a trend of blue-shifted emission from Ga to In complexes in terms of the peak wavelength is more obvious than that of the absorption spectra. For example, an emission spectral blue shift of $1175 \mathrm{~cm}^{-1}$ was resolved from $\mathbf{1 a}$ to $\mathbf{1 b}$, while it becomes as large as $2050 \mathrm{~cm}^{-1}$ from $\mathbf{3 a}$ to $\mathbf{3 b}$. The results simply indicate that the metal core, i.e. Ga versus In atom, in part, may play an important role in the observed electronic transition. Details on this issue are given in Theoretical Approach.

Another experimental result that has attracted our attention is the relatively low emission quantum efficiencies for both $\mathrm{Ga}$ $(\sim 0.1)$ and In $(\leq 0.03)$ complexes, considering that the title compounds are all fairly rigid according to the chelating ligand configuration. Moreover, with the same anchoring ligands, the emission quantum yield for the In complexes is apparently lower than that of the Ga complexes by nearly 1 order of magnitude (see Table 1). Since In element has an atomic number of 49 , which is apparently heavier than the gallium value of 31 , the results lead us to propose that the $\mathrm{S}_{1} \rightarrow \mathrm{T}_{n}$ intersystem crossing in these In complexes may serve as one major radiationless deactivating channel to compete with the $S_{1} \rightarrow S_{0}$ radiative decay. For this case, the heavier In atom should enhance the spin-orbit coupling, resulting in a fast $\mathrm{S}_{1} \rightarrow \mathrm{T}_{n}$ intersystem crossing rate. Likewise, the $\mathrm{T}_{1} \rightarrow \mathrm{S}_{0}$ radiative lifetime is expected to be shorter in the In complexes, rendering it feasible to resolve the phosphorescence. Support of this viewpoint is given by the phosphorescence measurements, in which the intensified charge coupled detector (ICCD) was electronically

(32) (a) Wu, P.-C.; Yu, J.-K.; Song, Y.-H.; Chi, Y.; Chou, P.-T.; Peng, S.-M.; Lee, G.-H. Organometallics 2003, 22, 4938. (b) Chao, T.-C.; Lin, Y.-T.; Yang, C.-Y.; Hung, T. S.; Chou, H.-C.; Wu, C.-C.; Wong, K.-T. Adv. Mater. 2005, 17, 992.

(33) (a) Chou, P.-T.; Chi, Y. Chem. Eur. J. 2007, 13, 380. (b) Chou, P.-T.; Chi, Y. Eur. J. Inorg. Chem. 2006, 3319. (c) Chi, Y.; Chou, P.-T. Chem. Soc. Rev. 2007, 36, 1421. 


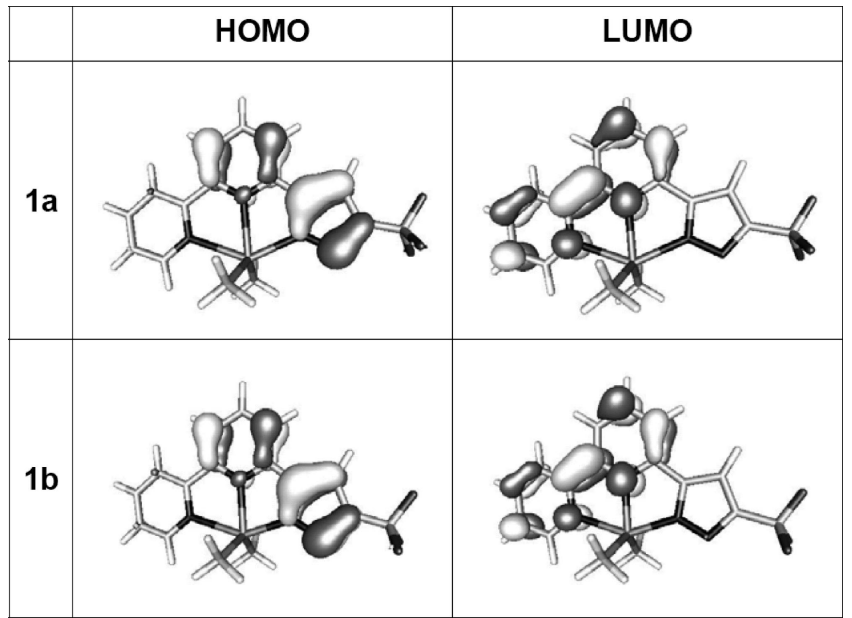

Figure 4. HOMO and LUMO of the representative complexes 1a,b.

gated at $1 \mathrm{~ms}$ with a delay time of $100 \mathrm{~ns}$ with respect to the excitation pulse to eliminate the prompt fluorescence and (see the Experimental Section). As a result, phosphorescence was resolved in the cases of $\mathbf{1 b}-\mathbf{3 b}$, with peak wavelengths centered at 510, 485, and $475 \mathrm{~nm}$, respectively (see Figure 3 for the phosphorescence spectrum of $\mathbf{1 b}$ ). On the other hand, under the same experimental conditions, phosphorescence was obscured for the Ga counterparts 1a-3a, manifesting their much lower efficiency in both $S_{1} \rightarrow T_{1}$ intersystem crossing and $T_{1}$ $\rightarrow \mathrm{S}_{0}$ radiative processes. Of course, for both $\mathrm{Ga}$ and $\mathrm{In}$ complexes, other radiationless deactivation pathways cannot be ignored. One prominent channel may be tentatively attributed to the shallow potential energy surface (PES) that arises from the distorted, highly strained trigonal-bipyramidal geometry, resulting in a possible intersection with respect to the groundstate PES and hence the radiationless deactivation.

3.4. Theoretical Approach. Theoretical confirmation of the underlying basis for the photophysical properties of compounds $\mathbf{1 a}-\mathbf{3 a}$ and $\mathbf{1 b}-\mathbf{3 b}$ was provided by DFT calculations. By using the TD-B3LYP/6-31G* and LANL2DZ method based on the fully optimized geometries, the vertical (i.e., Franck-Condon) excitation energy from the ground state to low-lying excited states was calculated. Figure 4 depicts the features of the lowest unoccupied (LUMO) and the highest occupied (HOMO) frontier orbitals for the studied representative complexes 1a,b involved in the lowest lying singlet transition, while the pertinent descriptions and the energy gap of all complexes are listed in Table 2. When the experimental results are compared (Table 1), the energy gaps for all complexes estimated from the theoretical approaches show the consistent tendency. For example, the calculated $S_{0}-S_{1}$ energy gap increases in the order $\mathbf{1 a}<\mathbf{2 a}<\mathbf{3 a}$ and $\mathbf{1 b}<\mathbf{2 b}<\mathbf{3 b}$. Also, in good agreement with the experimental results, the $S_{0}-S_{1}$ energy gap is larger in the In complexes in comparison to its Ga counterparts bearing identical ligands. In view of the quantitative approach, it is worth noting that the rather small deviation of the current theoretical approach from the experimental results may support the suitability of the theoretical level adopted here for studying the photophysical properties of $\mathrm{Ga}$ and In complexes $1 \mathbf{a}-\mathbf{3 a}$ and $\mathbf{1 b}-\mathbf{3 b}$.

Moreover, in $\mathbf{1 a}-\mathbf{3 a}$ and $\mathbf{1 b}-\mathbf{3 b}$, the associated frontier orbital data indicate that the electron densities of the HOMO are largely located on the azolate fragments and, in very small part, the central Ga or In atom (e.g., $<1 \%$ of the metal orbital in the HOMO of 1a,b), whereas those of the LUMO are mainly
Table 2. Calculated Energy Levels of the First Singlet Excited State for Complexes 1a-3a and $1 b-3 b$ Based on the Structural Optimized Geometries with the Integral Equation Formalism-Polarizable Continuum Model (in Acetonitrile), IEF-PCM

\begin{tabular}{|c|c|c|c|c|}
\hline $\mathrm{S}_{1}$ & calcd $\lambda_{\max }(\mathrm{nm})$ & $f$ & assignts & $\begin{array}{c}\text { CT character } \\
(\%)^{b}\end{array}$ \\
\hline 1a & 350.3 & 0.1814 & HOMO $\rightarrow$ LUMO $(+91 \%)^{a}$ & 52.6 \\
\hline $\mathbf{2 a}$ & 330.2 & 0.1581 & HOMO $\rightarrow$ LUMO (+91\%) & 32.7 \\
\hline 3a & 322.1 & 0.0505 & HOMO $\rightarrow$ LUMO $(+96 \%)$ & 3.3 \\
\hline 1b & 349.8 & 0.1891 & HOMO $\rightarrow$ LUMO (+91\%) & 51.6 \\
\hline $2 \mathbf{b}$ & 328.6 & 0.2232 & HOMO $\rightarrow$ LUMO $(+90 \%)$ & 38.9 \\
\hline 3b & 313.8 & 0.2743 & $\mathrm{HOMO} \rightarrow$ LUMO $(+87 \%)$ & 22.5 \\
\hline
\end{tabular}

${ }^{a}$ Transition probability. ${ }^{b} \mathrm{CT}$ character for the HOMO $\rightarrow$ LUMO transition is defined according to the equation $\left(\% \mathrm{HOMO}_{\text {azolate }}-\%\right.$ $\left.\mathrm{LUMO}_{\text {azolate }}\right) \times$ transition probability $(\%)$. Note that details of the molecular orbital compositions for $\mathbf{1 a}-\mathbf{3 a}$ and $\mathbf{1 b}-\mathbf{3 b}$ are provided in the Supporting Information.

distributed on the bipyridyl segment. Since the first singlet excited state of all title complexes mainly consists of the transition from HOMO to LUMO ( $>80 \%$; see Table 2$)$ the result clearly indicates that the lowest singlet electronic transition in $\mathbf{1 a}-\mathbf{3 a}$ and $\mathbf{1 b}-\mathbf{3 b}$ is dominated by $\pi$ (azolate) $\rightarrow \pi^{*}$ (pyridyl) intraligand charge transfer (ILCT), mixed with small but nonnegligible metal-to-ligand charge transfer (MLCT) character. As for $\mathbf{3 a}, \mathbf{b}$, the orbital compositions of the HOMO are found to be no longer dominated by the tetrazolate fragment, the result of which may be explained by the largely decreased tetrazolate orbital energy (see Table 2 for the charge transfer character analysis). Instead, the HOMO is located on the methyl groups and the whole tridentate ligand in $\mathbf{3 a}, \mathbf{b}$, respectively. Nevertheless, for all title $\mathbf{1 a}-\mathbf{3 a}$ and $\mathbf{1} \mathbf{b}-\mathbf{3 b}$ complexes, one can perceive that the nitrogen atom in the azolate moiety acts as an electronwithdrawing substituent and hence affects the HOMO energy level, giving a systematic variation of the photophysical properties. For instance, on comparison of the pyrazolate group in $1 \mathbf{a}(\mathbf{1 b})$ and the triazolate moiety in $\mathbf{2 a}(\mathbf{2 b})$, to which the HOMO is mainly contributed, an increase of the energy gap with a tendency of $\mathbf{1 a}<\mathbf{2} \mathbf{a}(\mathbf{1 b}<\mathbf{2} \mathbf{b})$ is well justified. In addition, one may speculate that the substituent effect of the azolate moiety, acting as an electron-withdrawing group with respect to the bipyridyl fragment, should also lower the relative energy of the LUMO. However, this effect seems to be minor, due to the extended conjugation between two bipyridyl moieties that contribute to the LUMO. Consequently, for the title complexes it is generally true that the $\mathrm{S}_{0}-\mathrm{S}_{1}$ energy gap, as reflected from either absorption or emission spectra, increases as the number of nitrogen atoms in the azolate moiety increases.

With regard to the notable difference between Ga and In complexes bearing identical ligand configurations, one possible explanation lies in the relative energy level of the valence orbital, namely $4 p$ for gallium and $5 p$ for indium. However, the ionization potential of the $\mathrm{Ga}$ (III) orbital is found to be higher than that of the In(III) orbital. ${ }^{34}$ Thus, upon mixing $\pi \pi^{*}$ and MLCT states, the lowest lying absorption/emission energy gap of In complexes is expected to be smaller than that of their $\mathrm{Ga}$ counterparts, contradicting the experimental results. The results also indirectly indicate a rather small contribution of the metal atom to the HOMO of the title Ga and In complexes, consistent with the theoretical data. Alternatively, owing to the different bonding strengths between $\mathrm{Ga}$ and In, the results may be

(34) Lide, D. R. CRC Handbook of Chemistry and Physics, 74th ed.; CRC Press: Boca Raton, FL, 1993; pp 10-205-10-207. 


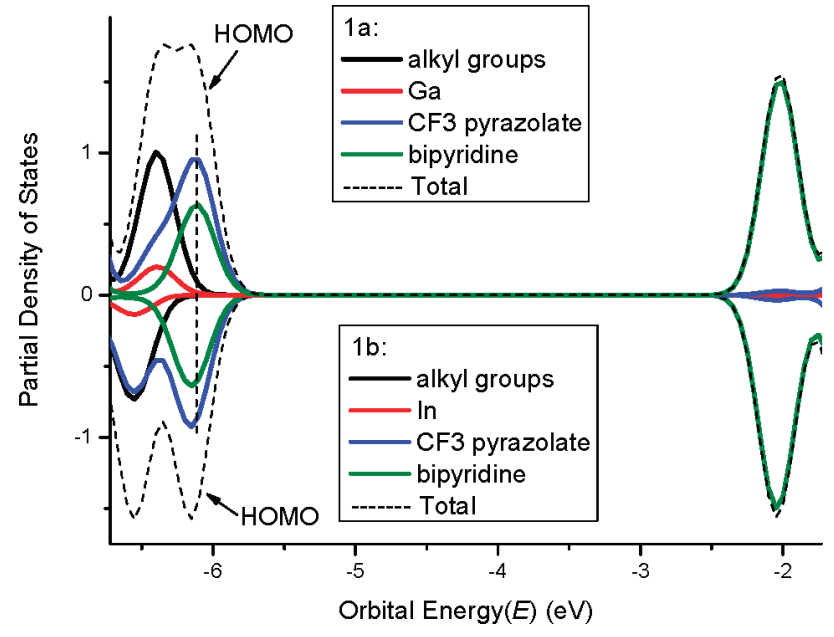

Figure 5. Plot of partial density of states of the representative complexes $\mathbf{1 a}, \mathbf{b}$.

rationalized by the lowering of the electron density of the azolate moiety in the In complex in comparison to that in the $\mathrm{Ga}$ counterpart.

A firm support of this viewpoint is given by a plot of partial density of states for $\mathbf{1 a}$ versus $\mathbf{1 b}$ extracted from the computation results. As depicted in Figure 5, the partial density of states of complexes 1a,b were intuitively divided into four fragments, namely methyl groups (fragment 1), the central metal atom (fragment 2), $\mathrm{CF}_{3}$-substituted pyrazolate (fragment 3), and bipyridyl ligand (fragment 4). For clarity, continuous Gaussian function curves are applied to represent the density of states for each fragment. The Gaussian functions appearing on the left side of Figure 5 are the electron density populations of the occupied states, while those depicted on the right-hand side are the electron density populations of the unoccupied states. Clearly, as shown by the peak location of the highest occupied orbital in Figure 5, the energy for those fragments belonging to $\mathrm{CF}_{3}$-substituted pyrazolate ligands of the indium complex $\mathbf{1 b}$ $(-6.15 \mathrm{eV})$ was significantly lower than that of its gallium counterpart 1a $(-6.11 \mathrm{eV})$, supporting the proposed mechanism. From the viewpoint of classical chemistry, owing to a stronger ligand field strength for the heavy element, one may perceive a greater bonding strength between In and azolates (versus $\mathrm{Ga}$ and azolates), resulting in more electron deficiency for the HOMO and hence an increase of the corresponding $\mathrm{S}_{0} \rightarrow \mathrm{S}_{1}$ transition gap.

\section{Conclusion}

In summary, 6-azolyl-2,2'-bipyridine ligands consisting a variety of pyrazolyl, triazolyl, and tetrazolyl substituents have been synthesized. Treatment of these tridentate ligands with the group 13 metal alkyl reagents $\mathrm{GaMe}_{3}$ and $\mathrm{InMe}_{3}$ yielded a series of new emissive metal complexes possessing the aforementioned 6-azolyl-2,2'-bipyridine chelates. Their chemical stability appears to be due to the pentacoordinate ligand environment, which is further confirmed by the formation of complex $\mathbf{4}$ via reaction of the bidentate (pyN4)H with $\mathrm{InMe}_{3}$, giving a self-assembled dimeric structure with two pentacoordinate In metal centers. Both the absorption and the corresponding emission peak positions of $\mathbf{1}-\mathbf{3}$ can be fine-tuned via the variation of azolyl functional groups, for which a rational explanation is provided by the HOMO/LUMO correlation via the assistance of computational approaches. We anticipate that such a design strategy might provide new insight into the preparation of main-group fluorescent dyes with good quantum yields and tunable emission hues that particularly fit into the current interest in OLEDs and related subjects.

Acknowledgment. This work was funded by the National Science Council of Taiwan, ROC, under Grant Nos. NSC 93-2113-M-007-012 and NSC 93-2752-M-002-002-PAE.

Supporting Information Available: CIF files giving X-ray crystallographic data for complexes $\mathbf{1 a}$ and $\mathbf{4}$ and figures and tables giving detailed computational results for the title complexes. This material is available free of charge via the Internet at http://pubs.acs.org.

OM700577Y 